\title{
IMPACT OF PV Plant ON Voltage VARIATIONS in Point of Common Coupling
}

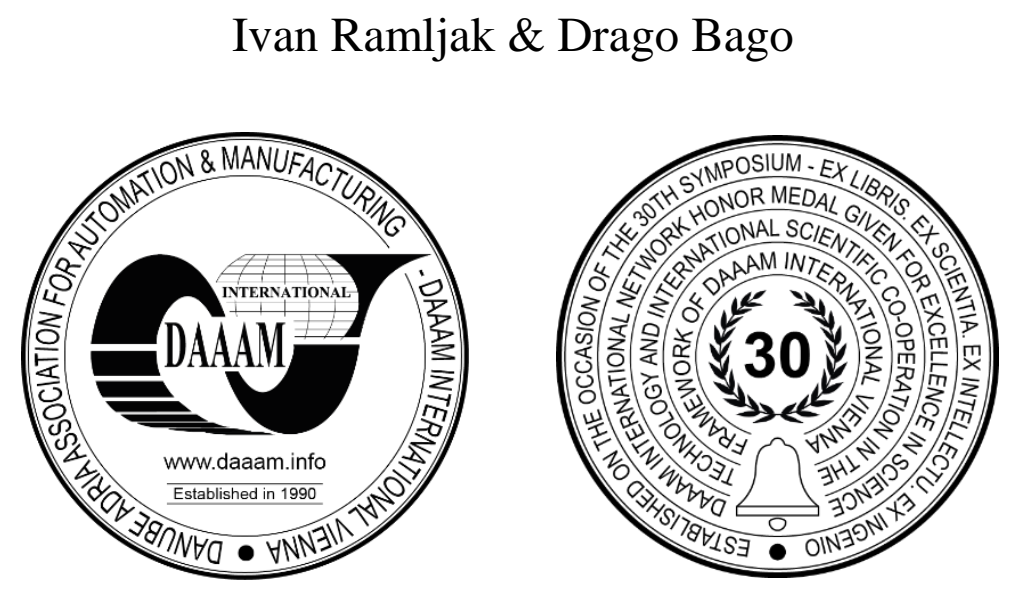

This Publication has to be referred as: Ramljak, I[van] \& Bago, D[rago] (2020). Impact of PV Plant on Voltage Variations in Point of Common Coupling, Proceedings of the 31st DAAAM International Symposium, pp.0842-0850, B. Katalinic (Ed.), Published by DAAAM International, ISBN 978-3-902734-29-7, ISSN 1726-9679, Vienna, Austria DOI: $10.2507 / 31$ st.daaam.proceedings. 118

\begin{abstract}
Renewable energy sources penetrate rapidly in electrical grid independently on voltage level. For low voltage grid, PV plants are main renewable source. Renewable energy sources in point of common coupling with power grid can have various influence on power grid in area of load flow, system protection, voltage quality etc. Very important item for PV plant integration in low voltage grid is potentially voltage quality degradation. This degradation can be for voltage harmonics, flickers, unbalance and voltage variations. Integration of PV plant in point of common coupling can rise voltage value in this point. This paper deals with analysis of voltage rising in point of common coupling for PV plant integrated in low voltage grid. First, impact of PV plant on voltage variation in point of common coupling will be analytical calculated for three case studies. Then, voltage measurement results will be analysed. Comparison of results will be presented. Analytical calculation method often used in practice will be examined for these case studies.
\end{abstract}

Keywords: PV plant; PCC; distribution grid; voltage

\section{Introduction}

Renewable sources (RES), or distributed generation (DG) is today very actual field in engineering technology. Every day number of MW penetrates into power grid worldwide. This high level of penetration is accompanied with development of technologies for DG development. However, high level of DG integration into power grid contributes to changes in conventional power grids. These changes are the most present in distribution grids, since conventionally these grids were consumption grids. Presence of DG in distribution grids is enabled by development of low power generators. These low power generators for distribution grids can be in range from $3 \mathrm{~kW}$ (converters for PV plants) to 2-3 MW (synchronous generators for small hydropower plants). This development of low power generators was a condition for high level DG penetration in distribution grids (low-voltage (LV) and middle-voltage (MV) distribution grids). Generally, DG development started with incentive schemes for development of these technologies due to high level CO2 emission from conventional thermal power plants. Usually DG sources in LV grids are converters of PV plants based on power electronic technology. MV grids are penetrated with different technology sources (synchronous and asynchronous generators and large scale converters). DG technology contributes to a cleaner power generation and reduces $\mathrm{CO} 2$ emission [1]. One of challenges for DG technologies is generation control. 
It means that DG, as for example PV plants and wind farms, are uncontrollable. Their generation is dependable on weather conditions, such as sunshine, wind blowing et al. [2]. This causes potentially extra expends in balancing of power systems with high share of DG sources. Energy storage in future may deal with these issues [3].

On the other hand, penetration of DG in distribution grids makes these grids active. This causes changes in distribution grids in terms of load flow, voltage quality, system protection et al. [4]. In distribution grids, conventionally, load flow was from transformer to consumer. Distribution grids, conventionally, were mostly radial grids with simple system protection approach and power loss analysis. Voltage quality potentially problems were mostly in voltage magnitude domain. DG penetration changes all these statements. For example, DG in distribution grid contributes to (regarding conventional distribution grid) a more complex load flow analysis, more complex setting of system protection, potentially higher power losses and potentially voltage quality degradation. Generally, these are the most exploited potentially problems with DG integration in distribution grid. With all this, hosting capacity of distribution grids as limit for DG integration becomes very important due to high share of DG integration in distribution grid [5].

It means that quantity of DG power and location of these in power grid topology is very important for DG integration, without negative impact on distribution grid. These all changes in distribution grid conception present challenge for distribution system operators (DSO). It can be concluded (from what is stated above) that technical requirements for DG integration in distribution grid are the most important issue for their successful integration [6].

This paper deals with integration of PV plant in LV distribution grid. Focus of this paper is with integration regarding voltage quality parameter - voltage RMS value variations. First, literature review of this issue will be presented. Then, comparison among simple analytical calculation method (often used) and measured results is presented. The idea was to check the correctness of mathematical calculation (analytically) for influence of PV plant on voltage variations in point of common coupling (PCC), due to PV plant integration. This correctness can be approved only by measuring voltage values for real PV plants integrated in LV grid. Then, comparison of these results (calculated and measured) can be performed. Finally, conclusion about correctness of analytically mathematical calculation for influence of PV plant on voltage variation due to PV plant integration in PCC can be drawn.

\section{Literature review}

PV plant can be integrated in LV grid in various locations (PCC). Regarding voltage quality, PV plant potentially infects LV grid in PCC by:

- Voltage value variations (RMS value of voltage)

- Harmonics (voltage and current harmonics)

- Flickers (short term and long term flickers)

- Unbalance (voltage unbalance).

There are some other parameters of voltage quality too, but those stated above are probably the most exploited [7]. This paper deals with voltage RMS value variation - potentially voltage rise of voltage RMS value after PV plant integration in PCC of LV grid. Generally, if PV plant size is relatively low regarding strength (short circuit power) of the grid, there is no significant negative influence of PV plant on voltage quality parameters in PCC. But, if PV plant size is relatively high regarding short circuit power of power grid in PCC, some potentially problems in area of voltage quality can occur [8].

Since this paper deals with potentially voltage RMS value rise after PV plant integration in PCC, first, analytical mathematical formulation for this will be presented. This mathematical formulation gives general and simple analytically model for calculation of potentially voltage rise in PCC (after DG integration):

$$
\Delta u(\%)=100 \cdot \frac{S_{r}}{S_{S C}} \cdot \cos \left(\psi_{k}+\phi\right)
$$

where $\psi_{k}$ is phase angle of the network impedance and $\phi$ is the phase angle of DG output current.

Equation (1) is simplified, but accurate enough for practical purposes [6]. From this equation is clear that worst case regarding voltage rise in PCC is for $\cos \left(\psi_{k}+\phi\right)=1$. If this is the case, voltage rise is the highest in regarded PCC. Further, voltage rise in PCC is simply dependent on two parameters, $S_{r}-$ rated power of PV plant (kVA) and $S_{S C}-$ short circuit power in PCC, strength of the grid (kVA). Rated power is power of converter(s) of PV plant, and short circuit power in PCC is strength of the grid (dependable on impedance of the power grid). This equation is highly used in practice for base analysis of PV plant influence on RMS voltage rise in PCC. But, exactly results can be obtained only by measurement [9]. This measurement should be performed in PCC (before and after PV plant integration).

Comparing analytically results obtained from equation (1) and results obtained by measuring, equation (1) can be confirmed in meaning of its correctness. Correctness of equation (1) will be examined for various case studies by measurement of voltage RMS values in PCC before and after PV plant integration. 


\section{Case studies}

This chapter presents three case studies of calculated and measured RMS voltage variations for various PV plants. Correctness of equation (1) will be examined for these case studies by measuring RMS voltage values after PV plant integration. Then, it will be examined is the equation (1), and when the equation (1) is usable for practical purposes.

For chosen case studies, next data are known:

- $S_{r}$ - rated power of PV plant (MVA)

- $S_{S C}-$ short circuit power in PCC, strength of the grid (MVA)

Knowing these data, analytically results from equation (1) can be obtained. Presented case studies are with followed data - Table 1.

\begin{tabular}{|c|c|c|c|}
\hline Case study & $\mathbf{1}$ & $\mathbf{2}$ & $\mathbf{3}$ \\
\hline$S_{r}(\mathrm{MVA})$ & 0,015 & 0,018 & 0,008 \\
\hline$S_{S C}(\mathrm{MVA})$ & 0,3 & 0,65 & 8 \\
\hline$S_{S C} / S_{r}$ & 20 & 36,21 & 1000 \\
\hline
\end{tabular}

Table. 1. Data of presented case studies

Case studies are numbered according to $S_{S C} / S_{r}$ ratio. This ratio presents strength of the grid. Case study 3 presents the strongest grid for analysed case studies. In all case studies, PV plants were integrated as shown in figure 1.

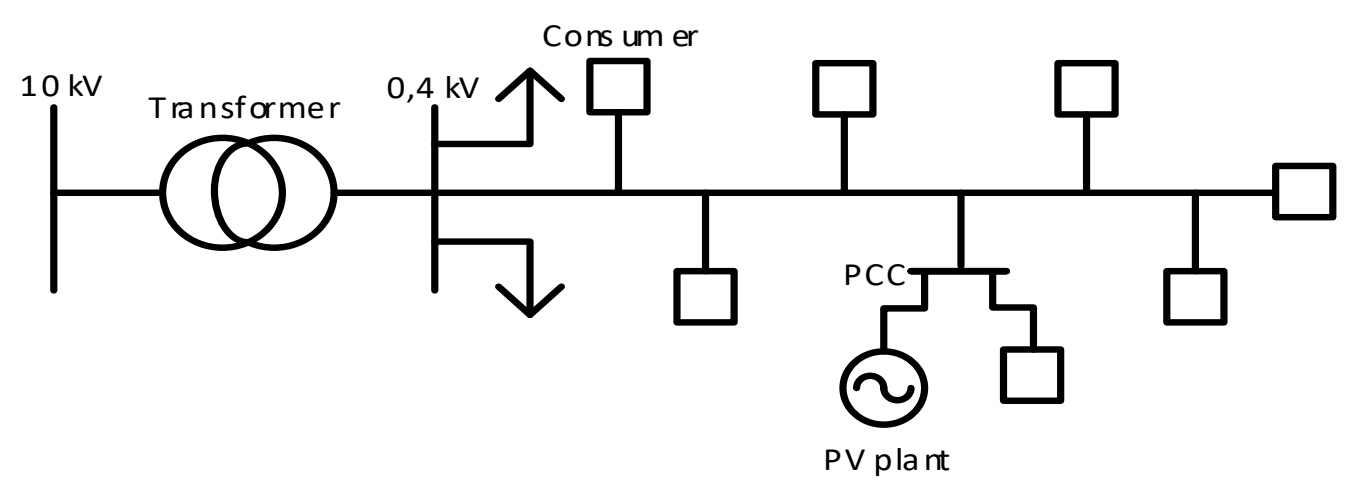

Fig. 1. Integration scheme of examined PV plants

\section{Results}

\subsection{Analytical results}

Analytical results of potential voltage rise for analysed case studies are presented in Table 2 .

\begin{tabular}{|c|c|c|c|}
\hline Case study & $\mathbf{1}$ & $\mathbf{2}$ & $\mathbf{3}$ \\
\hline$\Delta u(\%)$ & 5 & 2,77 & 0,1 \\
\hline
\end{tabular}

Table. 2. Analytical results of potential voltage rise.

It is obviously from Table 2 . that less solid grid $\left(S_{S C} / S_{r} \ll\right)$ means greater voltage rise - $\Delta u(\%)$.

\subsection{Measurement results}

After integration of subjected PV plants, measurement of voltage RMS value variations was performed in PCC. Measurements, for all three case studies, were performed with voltage quality instrument Class A (according to IEC 61000-4-30:2008). Measurements lasted for a week before and after PV plant integration, according to EN 50160:2012, with measurement period of 10 minutes (10-min) as stated in EN 50160:2012. It is the only wright way to analyse voltage RMS value variations after PV plant integration in PCC. Further, for each case study voltage RMS value variation in one 1 second (1-sec) period was analysed. It was done by measuring voltage values in period of inverter(s) synchronisation with LV grid in PCC. 
Figure 2. shows voltage values in form of $U_{\text {over }}(\%)$ - voltage value greater than nominal voltage value (of $\left.230 \mathrm{~V}\right)$ in percent, for case study 1. Results are presented for a period before PV plant integration in grid. On Figure 2., value of the highest $U_{\text {over }}(\%)$ for analysed period (3,54\%) is marked. This value is obtained from analysed period between 09:00 and 18:00. This period is chosen on basis of potentially PV plant generation if the one would be integrated. Measurement period is $10-\mathrm{min}$.

Figure 3. shows voltage values in form of $U_{\text {over }}(\%)$ - voltage value greater than nominal voltage value (of $\left.230 \mathrm{~V}\right)$ in percent, for case study 1. Results are presented for a period after PV plant integration in the grid. On Figure 3 . value of the highest $U_{\text {over }}(\%)$ for analysed period $(7,63 \%)$ is marked. This value is obtained from period in which PV plant was generating energy. Measurement period is 10 -min. Production power of PV plant in $\mathrm{kW}$ is shown too.

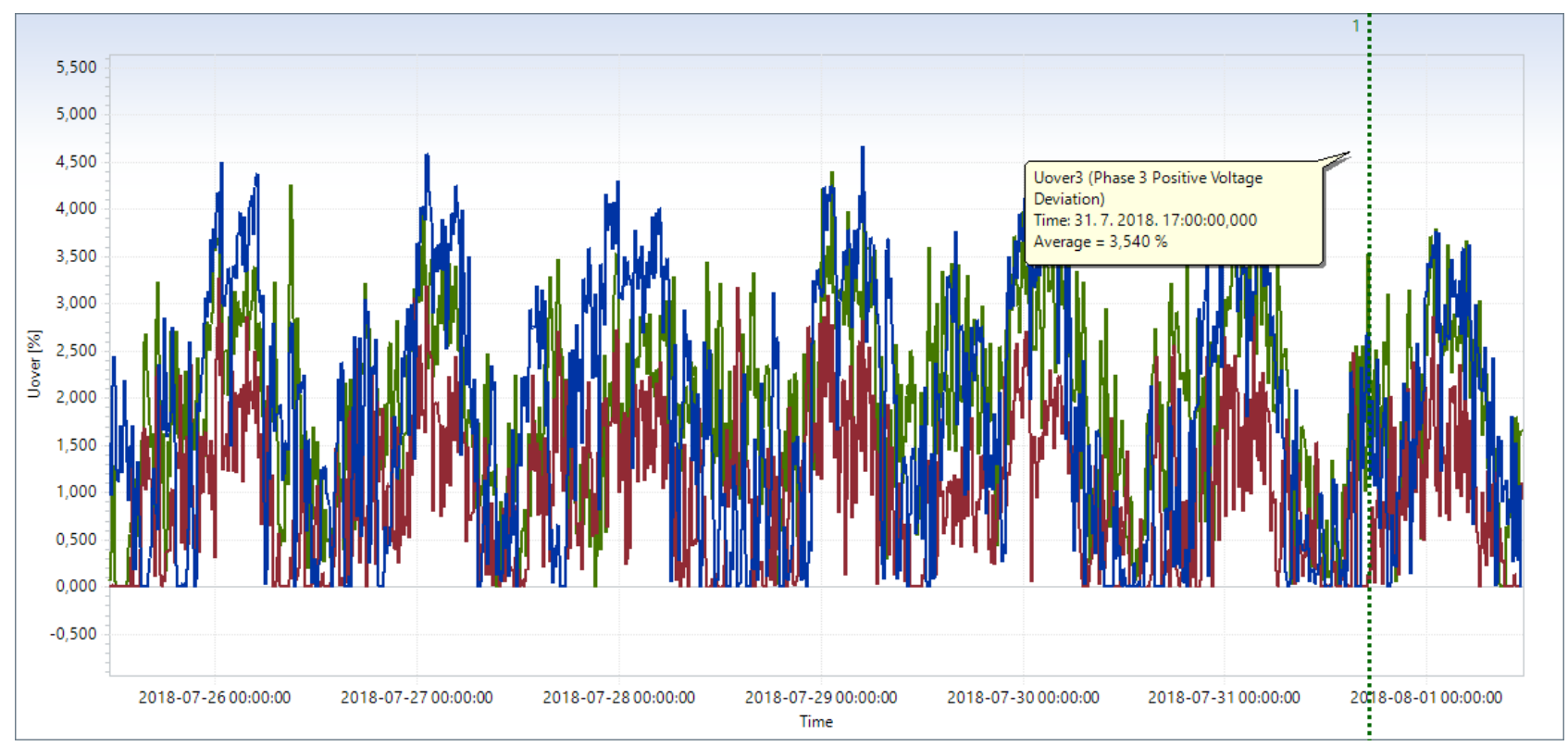

Fig. 2. Voltage values $\left(U_{\text {over }}(\%)\right)$ for case study 1 - before PV plant integration

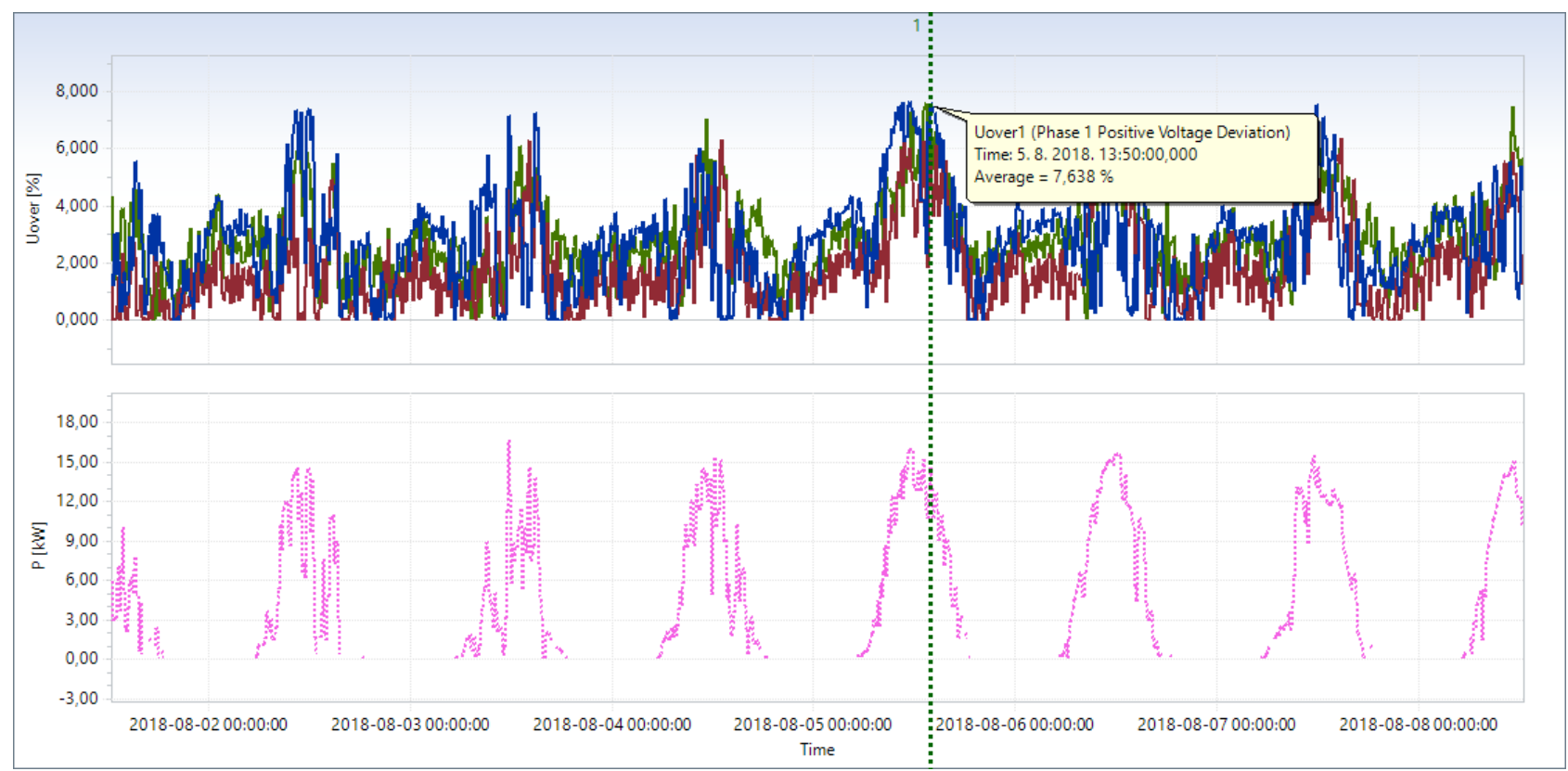

Fig. 3. Voltage values $\left(U_{\text {over }}(\%)\right)$ and generated power $(\mathrm{kW})$ for case study 1 - after PV plant integration

Figure 4. shows voltage values in form of Uover (\%) - voltage value greater than nominal voltage value (of $230 \mathrm{~V}$ ) in percent, for case study 1. Results are presented for a time period of PV plant integration on the power grid in a 1-sec measurement period. Production power of PV plant in $\mathrm{kW}$ is shown too. 


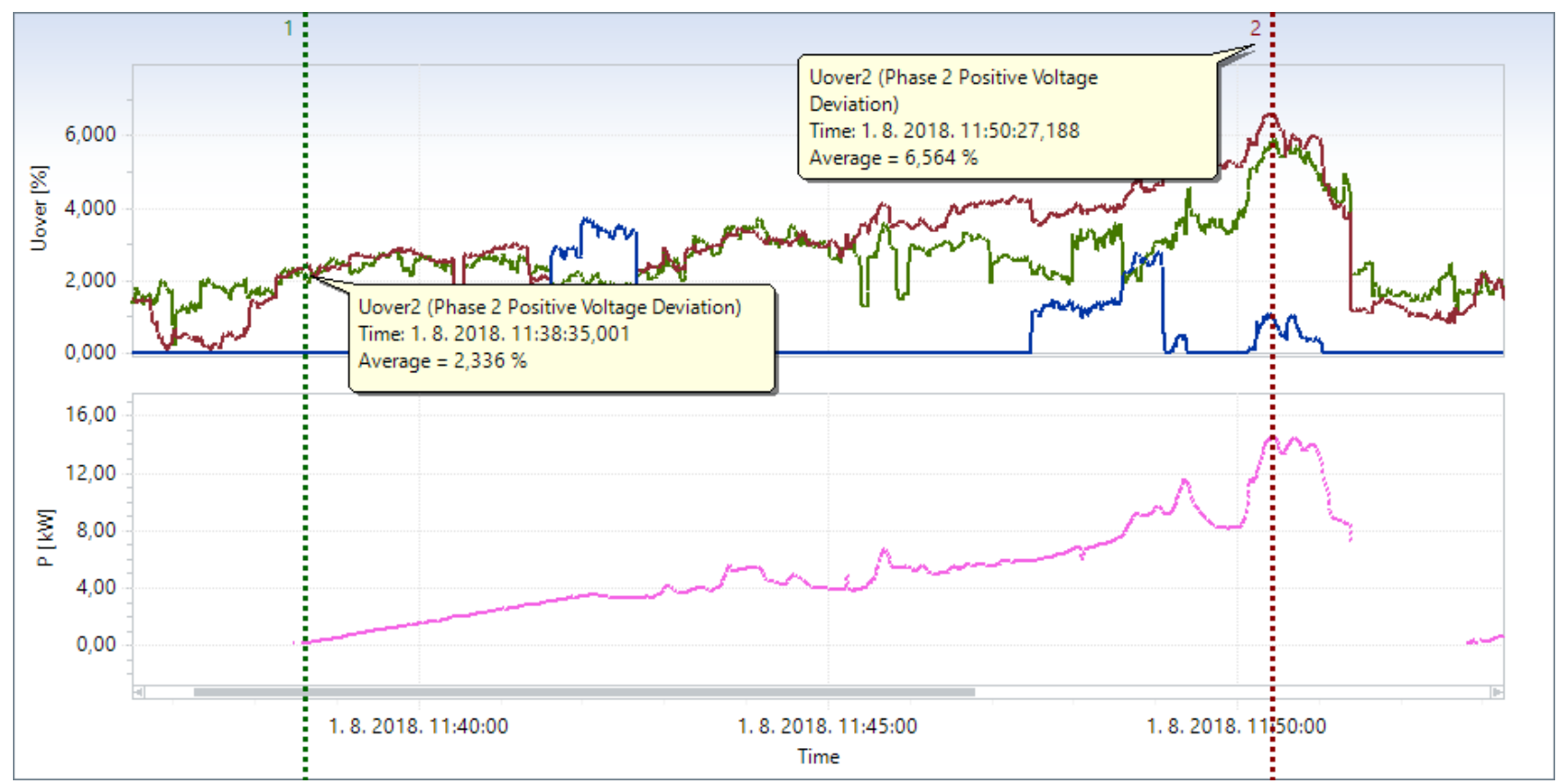

Fig. 4. Voltage values $\left(U_{\text {over }}(\%)\right)$ and generated power $(\mathrm{kW})$ for case study $1-\mathrm{PV}$ plant integration on the grid

Figure 5. shows line voltage values (V) for case study 2. Results are presented for a period before PV plant integration in grid. On Figure 5. value of the highest $(417,60 \mathrm{~V})$ and lowest line voltage is marked. This value is obtained from analysed period between 09:00 and 18:00. This period is chosen on basis of potentially PV plant generation if the one would be integrated. Measurement period is 10-min.

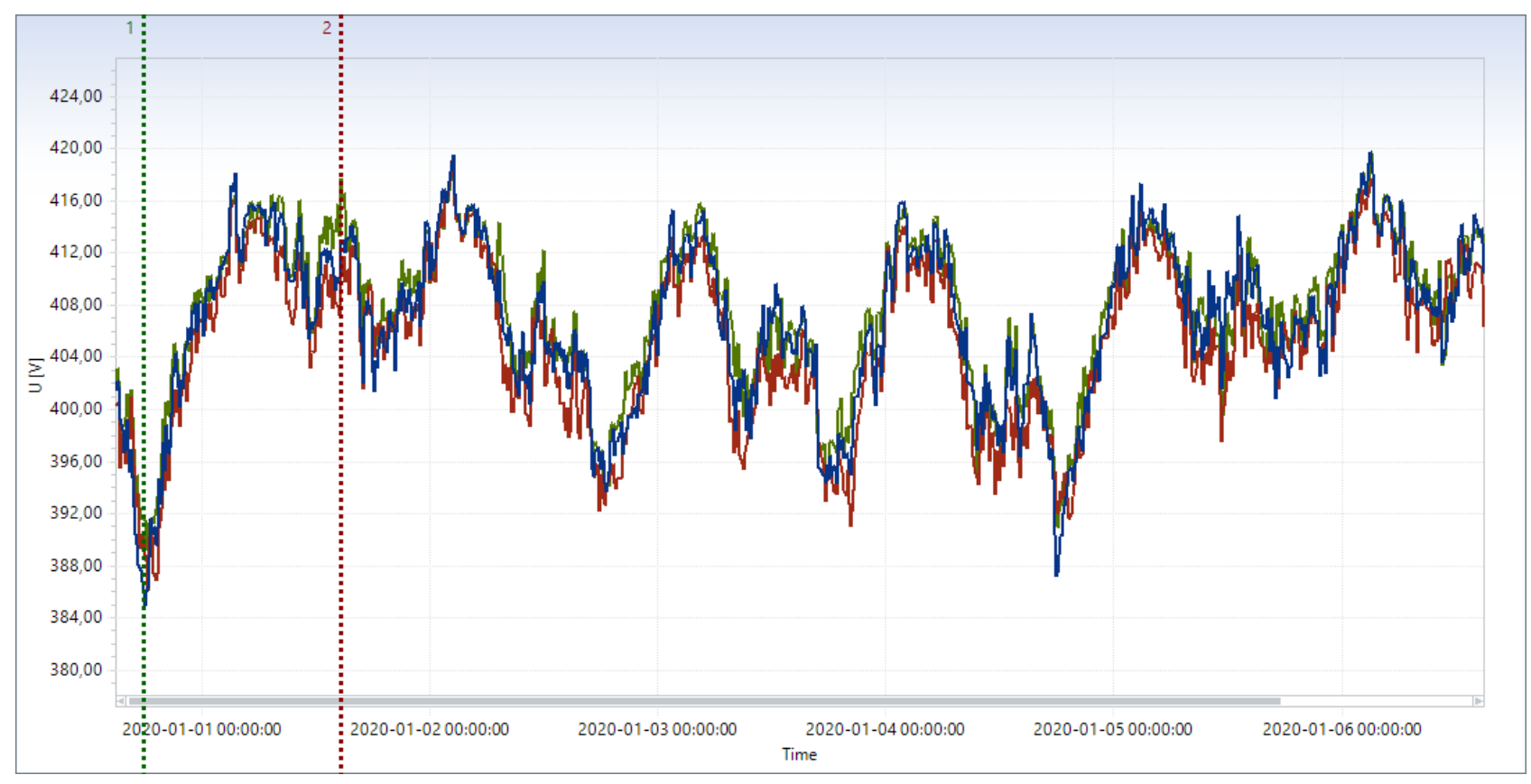

Fig. 5. Line voltage values for case study 2 - before PV plant integration

Figure 6. shows line voltage values (V) for case study 2. Results are presented for a period after PV plant integration in the grid. On Figure 6. value of the highest voltage for analysed period $(425,21 \mathrm{~V})$ is marked with dashed line 1 . This value is obtained from period in which PV plant was generating energy. Measurement period is 10-min. Rated current of $\mathrm{PV}$ plant generation (in A) is shown too. 


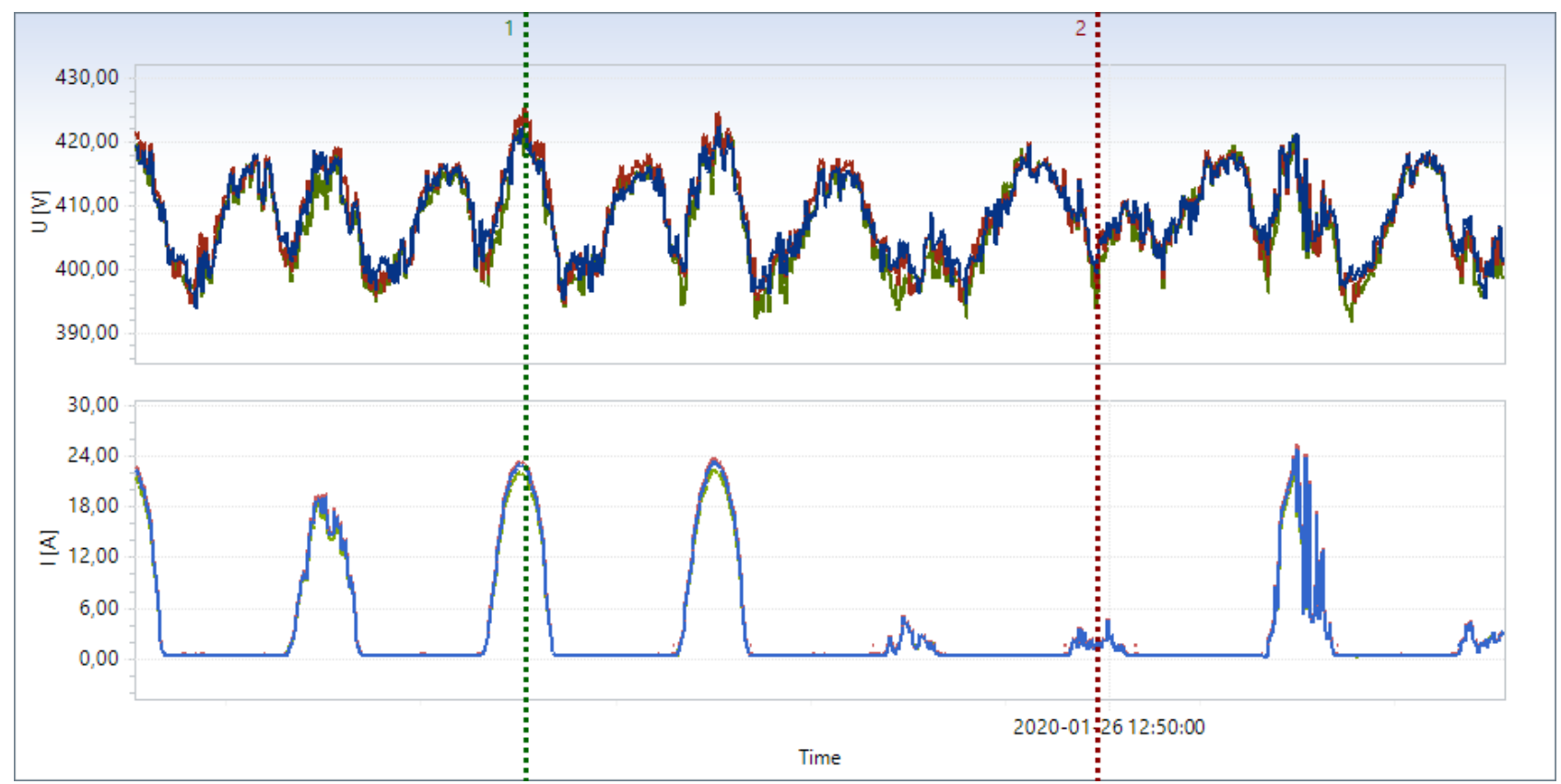

Fig. 6. Line voltage values (V) and generated current (A) for case study 2 - after PV plant integration

Figure 7. shows phase voltage values in phase L3 (V) for case study 2. Results are presented for a time period of PV plant integration on the power grid in a 1-sec measurement period. Phase L3 is chosen due to greatest voltage rise in this case. But, results are very similar for other two phases too. Rated current of PV plant generation (in A) is shown too for three phases.

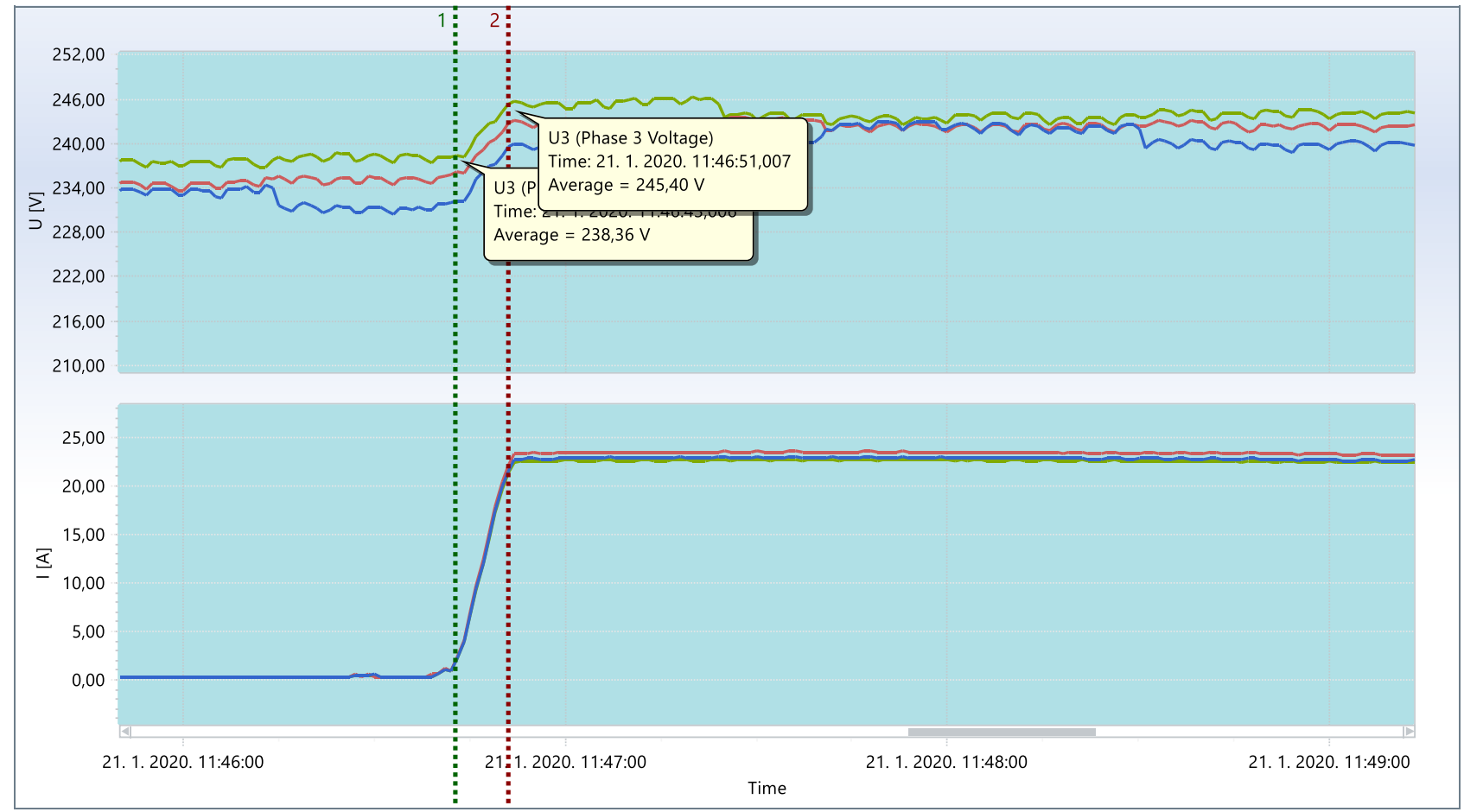

Fig. 7. Voltage values in $V$ (phase L3) and generated current (A) for case study 2 - PV plant integration on the grid

Figure 8. shows voltage values in form of $U_{\text {over }}(\%)$ and $U_{\text {under }}(\%)$ - voltage value greater/lower than nominal voltage value (of $230 \mathrm{~V}$ ) in percent, for case study 3. Results are presented for a period before PV plant integration in grid. On Figure 8 . value of the lowest $U_{\text {under }}(\%)$ for analysed period $(6,43 \%)$ is marked. This value is obtained from analysed period between 09:00 and 18:00. This period is chosen on basis of potentially PV plant generation if the one would be integrated. Measurement period is 10 -min. It is visible for this case study that for this case study $U_{\text {under }}(\%)$ values are predominated. 


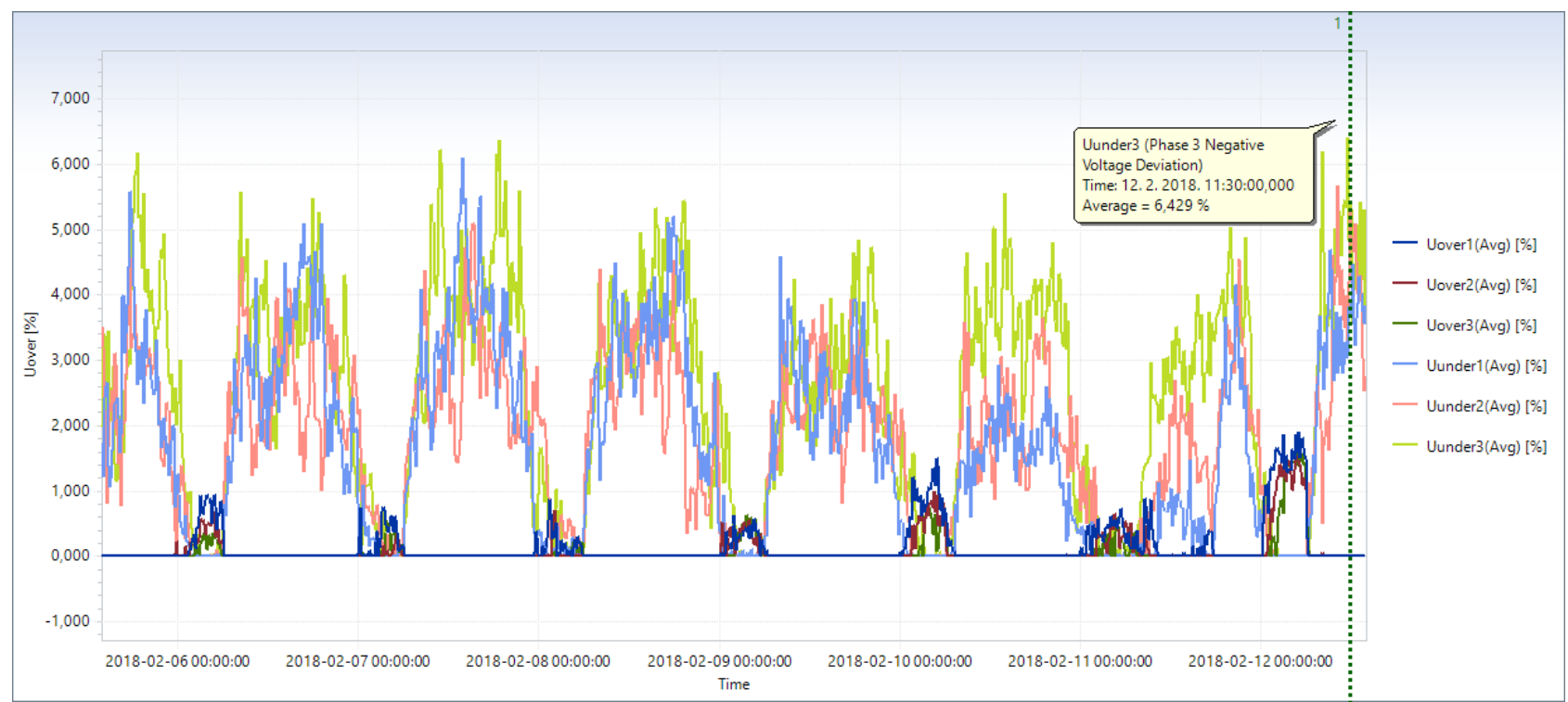

Fig. 8. Voltage values $\left(U_{\text {over }}(\%), U_{\text {under }}(\%)\right)$ for case study 3 - before PV plant integration

Figure 9. shows voltage values in form of $U_{\text {over }}(\%)$ and $U_{\text {under }}(\%)$ - voltage value greater/lower than nominal voltage value (of $230 \mathrm{~V}$ ) in percent, for case study 3. Results are presented for a period after PV plant integration in the grid. On Figure 9 . value of the lowest $U_{\text {under }}(\%)$ for analysed period $(7,53 \%)$ is marked. This value is obtained from period in which PV plant was generating energy. Measurement period is 10 -min.

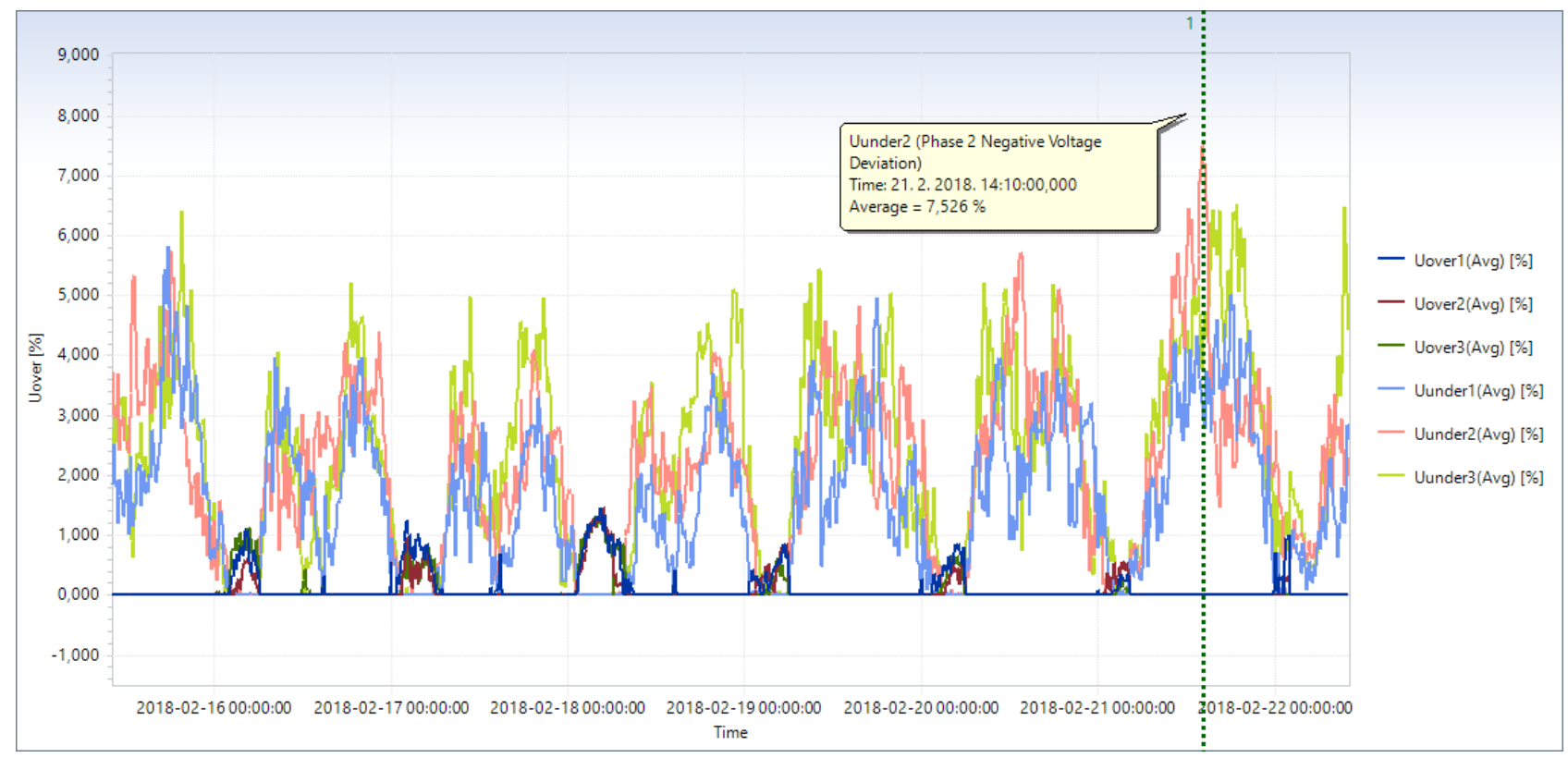

Fig. 9. Voltage values $\left(U_{\text {over }}(\%), U_{\text {under }}(\%)\right)$ for case study 3 - after PV plant integration

Figure 10. shows $U_{\text {under }}(\%)$ for case study 3 in phase L1. Similar results are for other two phases. Results are presented for a time period of PV plant integration on power grid in a 1-sec measurement period. $U_{\text {under }}(\%)$ values are marked with dashed lines in start and at the end of synchronisation period of PV plant on LV grid. Power generation in $\mathrm{kW}$ is presented too. 


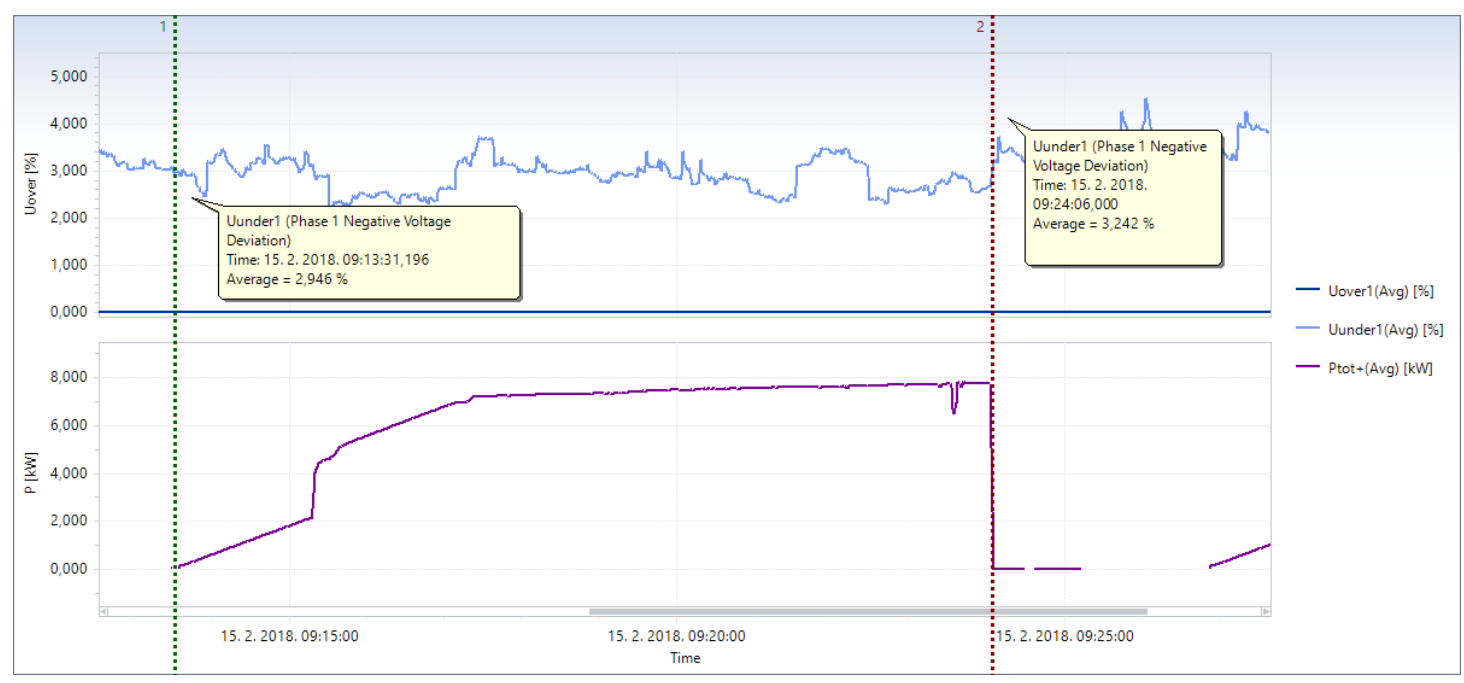

Fig. 10. Voltage values $U_{\text {under }}(\%)$ (phase L1) and generated power $(\mathrm{kW})$ for case study 3 - PV plant integration on the grid

\section{Discussion}

Generally, voltage drop/rise after PV plant integration can be calculated with:

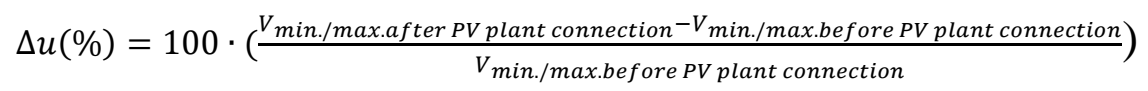

Results overview of voltage variations for these 3 case studies is presented in Table 3. for 10-min measurement period (in PCC). Results overview of voltage variations for these 3 case studies is presented in Table 4. for 1-sec measurement period (in PCC). Sign (+) in Table 3. and Table 4. means voltage rise. Sign (-) in Table 3. and Table 4. means voltage drop.

\begin{tabular}{|c|c|c|c|}
\hline Case study & $\mathbf{1}$ & $\mathbf{2}$ & $\mathbf{3}$ \\
\hline$\Delta \boldsymbol{u}(\%)$ & 4,1 & 1,79 & $-1,1$ \\
\hline
\end{tabular}

Table 3. Voltage variations for 10-min measurement period

\begin{tabular}{|c|c|c|c|}
\hline Case study & $\mathbf{1}$ & $\mathbf{2}$ & $\mathbf{3}$ \\
\hline$\Delta \boldsymbol{u}(\%)$ & 4,29 & 2,95 & $-0,3$ \\
\hline
\end{tabular}

Table 4. Voltage variations for 1-sec measurement period

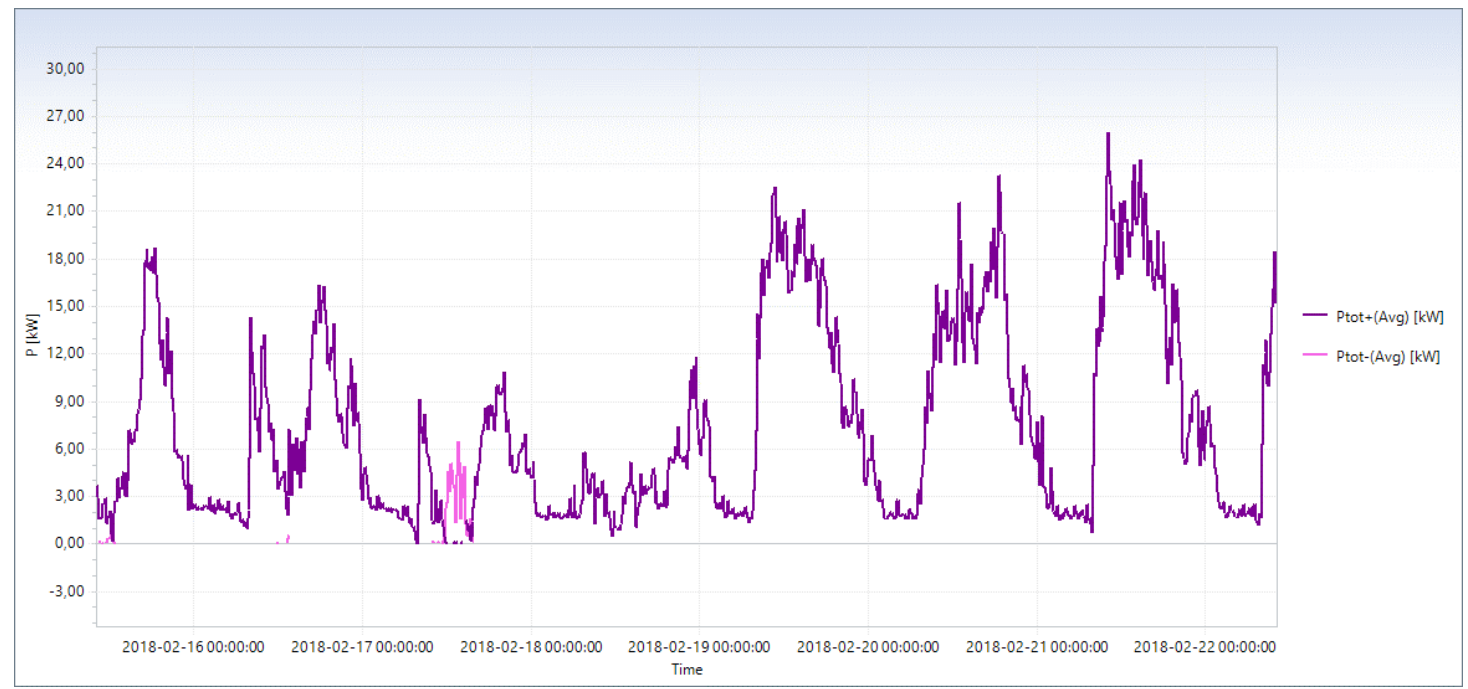

Fig. 11. Generated vs. consumed power (kW) in PCC for case study 3 
From Table 3. it is clear that less solid grid means greater voltage rise in PCC after PV plant integration. In case study 3 , voltage drop is present after PV plant integration in PCC. It is solid grid where consumption in and around PCC is greater than PV plant generation. In Figure 11. is shown that almost in all measured 10-min intervals generated energy by PV plant is consumed in (and around) PCC. In this Figure, Ptot+ presents power consumed by loads in PCC and $\mathrm{P}_{\text {tot }}{ }^{-}$ presents power generated by PV plant in PCC (to LV grid). This fact is actually limitation of analytical method because analytical method does not consider potentially voltage drop due to energy consumption in PCC. On the other hand, voltage drop after PV plant integration was not caused by PV plant (it exists due to energy consumption in PCC).

From Table 4. is clear that less solid grid means greater voltage rise in PCC after PV plant integration. In case study 3, voltage drop is present after PV plant integration in PCC. Comparing Table 3. and Table 4., voltage rise is greater in 1 -sec period than in 10-min period. Opposite, voltage drop is greater in 10-min period than in 1-sec period for case study 3. But, for case study 3, generated power (energy) by PV plant is consumed in (and around) PCC.

\section{Conclusion}

Problem analysed in this paper was level of voltage rise after PV plant integration in low voltage grid. That voltage rise can be problem if the one is above limited value. If that is the case, PV plant will be limited in energy production to the grid. It causes money losses to investors. Potentially voltage rise can be calculated before and measured after PV plant construction. Comparison of calculated and measured results is presented in this paper. This comparison answers to the question of accuracy of calculation method for solving of presented problem (so that is not the case after PV plant construction). It is obtained generally that in solid grid, after PV plant integration, the voltage rise does not have to occur. It is dependable on power consumption in PCC too. In less solid grid, after PV plant integration, voltage rises in PCC as more as grid is less solid. Shorter measurement period of voltage values means greater voltage rise in examined PCC (in less solid grids). Comparing calculated and measured results it is visible that calculated values (by (1)) should present worse results of voltage rise than measurement results. But, for solid grids, calculated voltage rise is not present in practice (measurements). For this case, voltage drop can occur (case study 3). It is dependable probably on power consumption in PCC. Generally, it can be concluded that results obtained by calculation should not be higher than the one obtained by measurement. So, analytical calculation is promising and accuracy method for voltage rise analysis in PCC for integration of PV plant. Limitation of this approach is lack of implementation in calculations of energy consumption in PCC (for existing consumers if they exist). Further work will be consisted on answering to following questions:

- Which $S_{S C} / S_{r}$ ratio presents solid grid (at which voltage rise would not be noticeable).

- How much influence already existing RES (the one at the same feeder) have on voltage rise in PCC where new PV plant would be integrated.

\section{Acknowledgements}

The authors would like to thank to JP Elektroprivreda HZ HB d.d Mostar for helping in issuing this paper.

\section{References}

[1] Jenkins, N.; Allan, P.; Crossley, D,; Kirschen, D. \& Strbac, G. (2000). Embedded Generation, The Institution of Engineering and Technology, ISBN: 9780852967744, London

[2] Chrobak, P.; Zalesak, M. \& Sehnalek, S. (2016). Photovoltaics and its potential application in the production of electricity, Proceedings of the 26th International DAAAM Symposium, October 2016, ISSN 1726-9679, ISBN 9783-902734-07-5, Katalinic, B. (Ed.), pp. 1032-1037, DAAAM International, Vienna, DOI: 10.2507/26th.daaam.proceedings. 145

[3] Huggins, R. (2010). Energy storage, Springer, ISBN: 978-1-4419-1024-0, New York

[4] Tokic, A. \& Milardic, V. (2015). Power quality (Kvalitet električne energije), PrintCom, ISBN: 978-9958-13-1066, Tuzla

[5] Bollen, M. \& Hassan, F. (2011). Integration of distributed generation in the power system, Wiley, ISBN: 978-1118-02902-2, New Jersey

[6] Papathanassiou, S.A. \& Hatziargyriou, N.D. (2001). Technical requirements for the connection of dispersed generation to the grid, Proceedings of IEEE PES Summer Meeting, July 2001, Vancouver, ISBN: 0-7803-7173-9, pp. 15-19, IEEE, New York, DOI: 10.1109/PESS.2001.970141

[7] Ramljak, I. \& Bago, D. (2018). Influence of PV plant connection on voltage quality parameters considering connection point in distribution grid, Proceedings of First International Colloquium on Smart Grid Metrology (SmaGriMet), April 2018, Split, ISBN: 978-9-5318-4235-8, Branimir Ivsic, Marko Jurcevic (Ed.), pp. 59-64, University of Zagreb, Zagreb, DOI: 10.23919/SMAGRIMET.2018.8369832

[8] Chicco, G.; Schlabbach, J. \& Spertino, F. Experimental assessment of the waveform distortion in grid-connected photovoltaic installations. Solar Energy. Vol. 83, No. 7, (July 2009), 1026-1039, ISSN 0038-092X, https://doi.org/10.1016/j.solener.2009.01.005

[9] Bago, D. \& Ramljak, I. (2019). Influence of PV plant 1 MWp connected on MV overhead line on voltage quality in PCC - case study, CIRED Proceedings, June 2019, Madrid, ISSN 2032-9644, ISBN: 978-2-9602415-0-1, pp. 1-5, AIM, http://dx.doi.org/10.34890/137 